\title{
Immunotargeting of collagenase on thrombus
}

This article was published in the following Dove Press journal:

International Journal of Nanomedicine

13 November 2010

Number of times this article has been viewed

Yi-ling Lu

Ben-xia Yang

Zong-ning Yin

Key Laboratory of Drug Targeting and Delivery System, West China School of Pharmacy, Sichuan University, Chengdu, Sichuan, People's Republic of China
Correspondence: Zong-ning Yin

West China School of Pharmacy, Sichuan University, Chengdu, Sichuan 61004I,

People's Republic of China

$\mathrm{Tel}+862885502917$

Fax+862885502917

Email yzn@scu.edu.cn

\begin{abstract}
In this study, we aimed to develop a thrombus-targeting delivery system of collagenase bound to a monoclonal antibody, and to investigate the thrombolysis of an immune-conjugate in vitro and in vivo as well as the targeting effect. We prepared the immunizing conjugation of collagenase by the 1-ethyl-3-(3-dimethylaminopropyl)-carbodiimide (EDCI) method. In order to conjugate collagenase and a monoclonal antibody, bovine serum albumin was used as a linker, increasing the number of collagenase molecules carried and keeping collagenase and the monoclonal antibody active. In vitro thrombolysis experiments showed that collagenase had a strong dissolving effect on collagen-embolus within 24 hours. We established a rabbit pulmonary embolism model to investigate the thrombolysis effect of collagenase and collagenase immunizing conjugation in vivo. Our results revealed a significant difference between collagenase and collagenase immunizing conjugation $(P<0.05)$. We also established a rabbit ear edge vein model to investigate the active target of collagenase immunizing conjugation. We found that collagenase immunizing conjugation had active targets, and had a strong ability to dissolve organized thrombi. In conclusion, the thrombus-targeting delivery system of collagenase we developed has active targeting effects on thrombi.
\end{abstract}

Keywords: thrombus-targeting, collagenase, monoclonal antibody

\section{Introduction}

Several agents are used to treat thromboembolic diseases. These agents can be classified by their mechanism of action as follows. ${ }^{1-4} 1$ ) Anticoagulants (such as heparin and coumarin), which prevent the formation of thrombi and the development of thrombi by interfering with the process of blood coagulation. 2) Antiplatelet drugs (such as aspirin, dipyridamole and hirudin), which inhibit the adhesion, aggregation and release of platelets to prevent the formation of thrombi. These drugs are usually used in the treatment of cardiovascular diseases, cerebral ischemia and peripheral embolism. 3) Thrombolytic agents (such as streptokinase, urokinase and tissue-type plasminogen activator), which convert zymogen plasminogen into an active form of serine proteinase plasmin, and then initiate or accelerate the process of fibrinolysis and degrade the fibrin network of thrombi and blood clots.

However, when apoplexy occurs and is not treated in time, the thrombus would become organized over time. Organization of the thrombus by cells of the surrounding vessel cells was demonstrated by Virchow and later confirmed by Aschoff.5,6 The matrix surrounding these cells was shown to be rich in collagen fibers. ${ }^{7}$ The collagen of an organized thrombus then interferes with the effect of thrombolysis. 
Streptokinase and fibrinolysin have been shown to have no effect on the solubility of native and denatured collagen, which could be degraded by collagenase. ${ }^{8}$ Collagenase is a type of proteolytic enzyme that can hydrolyze collagen at appropriate $\mathrm{pH}$ and temperature. Therefore, using collagenase would be a good strategy to dissolve an organized thrombus. Collagenase may achieve active targeting by binding to a monoclonal antibody or antibody fragment, such as third-generation thrombolytic agents which have a special affinity to organized thrombus. The immunizing conjugation of collagenase can be targeted to a thrombus and dissolve the thrombus effectively, and it also can reduce the side-effects of collagenase.

A drug and a monoclonal antibody can be crosslinked by chemical reactions. Then, the biological activity of the drug and antibody of conjugation should be sustained, and the toxicity of conjugation does not increase. In the past few years, the method of crosslinking a drug and a monoclonal antibody with a carrier has been widely used. An intermediate is first obtained from a drug combined with some compounds or polymers or vehicle, then the intermediate binds with a monoclonal antibody to form an immune-conjugate. The usual crosslinking reactions include direct oxidation, ${ }^{9}$ the dextran T-40 method, ${ }^{10}$ the activated ester method, ${ }^{11}$ the 1-ethyl-3-(3-dimethylaminopropyl)-carbodiimide (EDCI) method, ${ }^{12,13}$ the cyanogens bromide method, ${ }^{14}$ the mixed anhydride method, ${ }^{15}$ and so on. A reasonable crosslinking method should meet the following requirements: high yield of cured product, homogeneous composition, sustained activity, simple operation, good reproducibility, easy separation and purification.

\section{Materials and methods Materials}

Collagenase was purchased from the Shanghai Institute of Pharmaceutical Industry (Shanghai, China). Collagen, EDCI and anti-collagen monoclonal antibody (McAb) were purchased from Sigma (USA). Ninhydrin was purchased from Shanghai SSS Reagent (China). Bovine serum albumin (BSA) was purchased from Shanghai Bio-Life Science and Technology Co., Ltd (China). Fluorescein isothiocyanate (FITC) was purchased from Amresco (USA). Polyethylene glycol (PEG) 6000 was purchased from Bazhou Chemical Plant Factory of Tianjin Crystal Clock Factory (China).

Rabbits, of body weight of 2.0 to $2.5 \mathrm{~kg}$, were provided by the West China Laboratory Animal Center of
Sichuan University. All experiments were approved by the Institutional Animal Care and Use Committee of Sichuan University.

\section{Methods}

\section{Activity assay methods \\ Collagenase assay}

Ninhydrin-based assay: $:{ }^{16} 0.5 \mathrm{~mL}$ of solution was mixed with $0.5 \mathrm{~mL}$ of phosphate-buffered saline (PBS) $(0.05 \mathrm{~mol} / \mathrm{L}$, $\mathrm{pH} 7.4)$ in test tubes. Then $0.5 \mathrm{~mL}$ of collagenase of different concentrations and $0.5 \mathrm{~mL}$ of $\mathrm{CaCl}_{2}(0.05 \mathrm{~mol} / \mathrm{L})$ were separately added and the tubes were shaken evenly. The above mixtures were incubated at $37^{\circ} \mathrm{C}$ for 30 minutes, mixed with $0.5 \mathrm{~mL}$ of freshly prepared ninhydrin reagent and heated for 20 minutes in a boiling water bath. After cooling, the mixture was diluted with $1.5 \mathrm{~mL}$ of water to obtain appropriate concentrations for absorbance measurements, and then centrifuged for 5 minutes ( $8000 \mathrm{rpm})$. Absorbance was measured at $566 \mathrm{~nm}$ by a UV1000 Spectrophotometer (Shanghai, China).

\section{Stability of collagenase}

Stability of collagenase solution: Collagenase solution was stored at $4^{\circ} \mathrm{C}$ and sampled at different time points. Then the activities of the samples were determined by ninhydrinbased assay.

Thermal stability of collagenase solution: Collagenase solution was incubated at different temperatures and sampled at different time points. Then the activities of the samples were determined by ninhydrin-based assay.

\section{Selection of crosslink agent}

Several crosslink agents (glutaraldehyde, succinimide, acetone, EDCI) were mixed with collagenase and the activity of the collagenase was determined.

\section{McAb assay (enzyme-linked immunosorbent assay)}

Enzyme-linked immunosorbent assay (ELISA) was performed with washes in PBS pH 7.4 containing $0.05 \%$ Tween-20, 0.1\% BSA, $2 \times 10^{-3}$ EDTA (PBS-Tween-BSAEDTA) between each step. ELISA plates were coated by collagen diluted in $0.05 \mathrm{~mol} / \mathrm{L}$ Tris- $\mathrm{HCl}$ buffer $(\mathrm{pH} 7.6$, containing $0.15 \mathrm{~mol} / \mathrm{L} \mathrm{NaCl}$ ). After overnight incubation at $4{ }^{\circ} \mathrm{C}$, plates were blocked for 20 hours at $4{ }^{\circ} \mathrm{C}$ in $\mathrm{PBS} \mathrm{pH}$ 7.4 containing $0.1 \%$ BSA and $0.05 \%$ Tween-20, before adding the samples appropriately diluted in PBS-TweenBSA-EDTA. After overnight incubation at $4{ }^{\circ} \mathrm{C}$, monoclonal 
anti-collagen was detected by incubating at $37^{\circ} \mathrm{C}$ for 1 hour with a horseradish peroxidase-labeled goat polyclonal antibody (diluted in 1:1000 by PBS-Tween-BSA-EDTA). Then, the enzyme substrate ortho-phenylenediamine ( $1 \mathrm{mg} / \mathrm{mL}$ in citrate buffer solution $\mathrm{pH} 4.5$ adding $30 \% \mathrm{H}_{2} \mathrm{O}_{2}$ $1 \mu \mathrm{L} / \mathrm{mL}$, prepared before reaction) was added to the plate and reacted exactly for 10 minutes at room temperature. Enzyme reaction was stopped by adding $2 \mathrm{~mol} / \mathrm{L}$ sulfuric acid solution. Absorbance was measured at $490 \mathrm{~nm}$ on a microplate reader.

\section{Preparation of collagenase-BSA-anti- collagen monoclonal antibody (Coll.-BSA-McAb) immune-conjugate}

Coll.-BSA conjugate was prepared by the EDCI method. ${ }^{17-19}$ Then the conjugate was separated from free collagenase and BSA by passing the mixture through a Sephadex G25 gel (Sigma, USA) exclusion chromatography (GEC) column with purified water as eluent and condensed by PEG 6000 to $1.5 \mathrm{~mL}$.

The purified and concentrated Coll.-BSA was mixed with $0.5 \mathrm{~mL}$ EDCI $(1 \mathrm{mg} / \mathrm{mL})$ and $50 \mu \mathrm{L}$ anti-collagen monoclonal antibody solution, and then the mixture was churned in an ice-cold water bath for 30 minutes. Subsequently, the conjugate was separated from free collagenase and BSA by passing the mixture through a Sephadex G25 GEC column with purified water as eluent and condensed by PEG 6000 to $1.5 \mathrm{~mL}$.

\section{Measuring the effect of Coll.-BSA-McAb on thrombolysis in vitro}

Preparation of collagen-coated thrombi

The collagen solution ( $4 \mathrm{mg} / \mathrm{mL}$, dissolved with $0.05 \mathrm{~mol} / \mathrm{L}$ acetic acid $)$ neutralized by $\mathrm{NaOH}(0.5 \mathrm{~mol} / \mathrm{mL})$ was injected into an enclosed polyethylene plastic tube (length: $20 \mathrm{~cm}$, internal diameter: $2.5 \mathrm{~mm}$ ), and then the tube was incubated in a water bath at $37^{\circ} \mathrm{C}$ for 15 minutes. Fresh blood from rabbit ear vein was injected into the pre-heated tube with inner collagen coating, and the tube was incubated in a water bath at $37^{\circ} \mathrm{C}$ for 30 minutes. Finally, the collagen-coated thrombi was pushed out from the tube and cut into pieces $2 \mathrm{~cm}$ long.

\section{Determining thrombi weight}

A series of collagen-coated thrombi were weighed, put into $0.01 \mathrm{~mol} / \mathrm{L} \mathrm{pH7.4} \mathrm{PBS} \mathrm{(containing} \mathrm{0.9 \%} \mathrm{NaCl),} \mathrm{taken} \mathrm{out,}$ blotted dry on filter paper and weighed $\left(\mathrm{W}_{\mathrm{n}}\right)$ at set time points.
Then the thrombi were put into PBS again. This procedure was repeated 3 times.

\section{Thrombolysis assay in vitro}

The effect of Coll.-BSA-McAb immune-conjugate on thrombolysis in vitro was examined by a circulation system (Figure 1). Briefly, the channels were connected by polyethylene plastic tubes (length: $70 \mathrm{~cm}$, and internal diameter: $2.5 \mathrm{~mm}$ ) and glass tubes (length: $6 \mathrm{~cm}$, and internal diameter: $7.5 \mathrm{~mm}$ ), and 2 terminals were sealed by rubber plugs. Three bottles of sample solution, which were prepared by PBS (pH $7.40,0.01 \mathrm{~mol} / \mathrm{L}$ ), were incubated in a water bath at $37^{\circ} \mathrm{C}$. In order to simulate the circulation system, the driving force was provided by a peristaltic pump, and a constant flow rate was set at $2 \mathrm{~mL} / \mathrm{min}$.

The collagen emboli were taken out, blotted dry on filter papers and weighed $\left(\mathrm{W}_{\mathrm{n}}\right)$ at set time points, and then put in the glass tubes. The thrombolysis rate in vitro was calculated according to the following formula: thrombolysis rate $(\%)=$ $\left[\left(\mathrm{W}_{0}-\mathrm{W}_{\mathrm{n}}\right) / \mathrm{W}_{0}\right] \times 100 \%$.

\section{Measuring the effect of Coll.-BSA-McAb immune-conjugate on thrombolysis in vivo Establishment of a pulmonary embolism model in rabbits}

A catheter was inserted into an external jugular vein of an anesthetized animal, and then 2 pieces of weighed emboli $\left(\mathrm{W}_{0}\right)$ (prepared as described above) were injected into the rabbit to generate a pulmonary embolism model. Subsequently, the catheter was ligatured, and the incision was sutured.

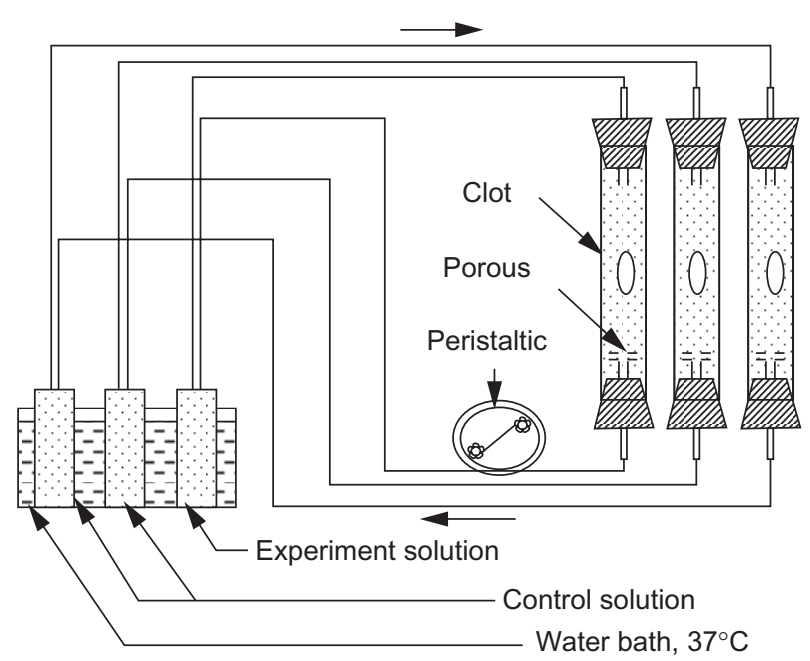

Figure I An abridged general view of the apparatus for measuring the effect of Coll.-BSA-McAb immune-conjugate on thrombolysis in vitro. 


\section{Thrombolysis assay in vivo}

Five minutes after embolus injection, the rabbits were intravenously administered with $15 \mathrm{~mL}$ blank normal saline (NS) solution (blank control group), collagenase NS solution (the standard group) and immunoconjugate NS solution (the experimental group), respectively. The rabbits were sacrificed by carotid artery exsanguinating 24 hours after the operation, and the hearts and lungs were dissected. Then, the incompletely dissolved emboli were dried with filter paper and weighed $\left(\mathrm{W}_{\mathrm{n}}\right)$. And the thrombolysis rate in vivo was calculated according to the following formula: thrombolysis rate $(\%)=\left[\left(\mathrm{W}_{0}-\mathrm{W}_{\mathrm{n}}\right) / \mathrm{W}_{0}\right] \times 100 \%$.

\section{Measuring the targeting effect of Coll.-BSA-McAb immune-conjugate}

Establishment of an ear vein embolism model in rabbits

In 1856, Virchow proposed a classic view about the factors (such as abnormal changes of the blood vessel wall, constituents of blood and blood flow) that influence thrombosis development. ${ }^{20}$ Injuring the blood vessel endothelium is a general method of thrombosis. ${ }^{21}$ Briefly, \#8 syringe needles were processed as follows: the tips of the needles were blunted, and the edges of the needle tubes were roughened. The modified needles were pierced into ear vein of rabbit, and the blood vessel wall was repeatedly rubbed by the needle. Then the puncture point was compressed to staunch bleeding, and a marker was made at the embolism site.

\section{Coll.-BSA-McAb immune-conjugate labeled by FITC}

The FITC solution dissolved in buffer bicarbonate $(\mathrm{pH}$ 9.5) was added drop by drop into collagenase immunizing conjugation solution. The mixture was churned in an icecold water bath for 2 hours $(\mathrm{pH}>9)$. Then the mixture was purified by Sephadex G25 column $(20 \times 2.2 \mathrm{~cm})$ with water as eluent. The first eluent section was collected, and the collagenase immunizing conjugation was labeled by FITC (FITC-Coll.-BSA-McAb).

\section{Evaluation of the thrombotic targeting of conjugate in rabbits}

After the ear vein embolism model was established, all rabbits were injected with $0.5 \mathrm{~mL}$ drug solution above a thrombotic blood vessel on day 7. Rabbits were intravenously administered either with FITC-Coll.-BSA-McAb NS solution (4 mg collagense per $\mathrm{kg}$ body weight) or FITC-collagenase NS solution (4 mg collagense per $\mathrm{kg}$ body weight), respectively, and then $10 \mathrm{~mL}$ NS solution was administered for both groups. After 1 hour, a marked segment of ear was processed to obtain frozen sections of $50 \mu \mathrm{m}$ thickness. The sections were photographed with a Leica DMR fluorescence microscope.

\section{Statistical analyses}

Data were analyzed by using $t$-tests and one-way ANOVA (S-N-K comparison). Data are expressed as mean $\pm \mathrm{SD}$ and differences considered significant when $P<0.05$.

\section{Results \\ Activity assay \\ Collagenase assay}

Assay study showed a linear increasing in the activities of collagenase with concentrations, with the regression equation of $\mathrm{A}=5.195 \mathrm{C}-0.1458(\mathrm{r}=0.9976)$ during the concentrations range of $0.04-0.20 \mathrm{mg} / \mathrm{mL}$.

\section{Stability of collagenase}

The results (Table 1) show that collagenase solution was stable for 2 hours at $4^{\circ} \mathrm{C}$. Table 2 showed that collagenase solution was sensitive to heat. Collagenase activity was unchanged for 2 hours at $25^{\circ} \mathrm{C}$, but dropped sharply at over $50^{\circ} \mathrm{C}$ and became almost inactive after 2 hours.

\section{Selection of crosslink agent}

Glutaraldehyde, succinimide and acetone clearly reduced collagenase activity. Because EDCI had the least influence on collagenase activity (Table 3 ), it was chosen as the crosslink agent.

\section{Preparation of immunoconjugate}

The activities of Coll., McAb in Coll.-McAb and Coll.$\mathrm{BSA}-\mathrm{McAb}$ were measure respectively after preparation. Table 4 shows that the activities of Coll. and McAb were both higher in immune-conjugate with BSA as linker than those in Coll.-McAb; and Figures 2 and 3 show that the activities

Table I The stability of collagenase solution $(n=3, \bar{X} \pm$ SD)

\begin{tabular}{lllllll}
\hline Time (h) & $\mathbf{0}$ & $\mathbf{0 . 5}$ & $\mathbf{I}$ & $\mathbf{2}$ & $\mathbf{4}$ & $\mathbf{6}$ \\
\hline $\mathrm{A}_{566 \mathrm{~nm}}$ & $0.499 \pm 0.022$ & $0.47 \pm 0.023$ & $0.504 \pm 0.019$ & $0.500 \pm 0.018$ & $0.431 \pm 0.021$ & $0.376 \pm 0.018$ \\
\hline
\end{tabular}


Table 2 Absorption of $A_{566 \mathrm{~nm}}$ of collagenase at different temperatures $(n=3, \bar{X} \pm S D)$

\begin{tabular}{lllll}
\hline $\begin{array}{l}\text { Time } \\
(\boldsymbol{m i n})\end{array}$ & \multicolumn{4}{l}{ Temperature $\left({ }^{\circ} \mathbf{C}\right)$} \\
\cline { 2 - 5 } & $\mathbf{2 5}$ & $\mathbf{3 7}$ & $\mathbf{5 0}$ & $\mathbf{6 0}$ \\
\hline 0 & & $0.514 \pm$ \\
30 & $0.529 \pm 0.002$ & $1.356 \pm 0.00 \mathrm{I}$ & $0.753 \pm 0.00 \mathrm{I}$ & $0.894 \pm 0.00 \mathrm{I}$ \\
60 & $0.569 \pm 0.002$ & $0.837 \pm 0.00 \mathrm{I}$ & $0.764 \pm 0.00 \mathrm{I}$ & $0.40 \mathrm{I} \pm 0.002$ \\
90 & $0.589 \pm 0.001$ & $0.726 \pm 0.003$ & $0.298 \pm 0.00 \mathrm{I}$ & $0.004 \pm 0.00 \mathrm{I}$ \\
120 & $0.579 \pm 0.001$ & $0.648 \pm 0.003$ & - & - \\
\hline
\end{tabular}

of Coll. and McAb in Coll.-BSA-McAb were higher than in Coll.-McAb.

\section{The effect of Coll.-BSA-McAb on thrombolysis in vitro Preparation of thrombi coating collagen}

A collagen embolus of good form and strength was obtain according to the method described in Preparation of collagen-coated thrombi (Figure 4). A collagen embolus was confirmed by the fluorescent layer coating the collagen embolus (Figure 5).

\section{Determining the weight of thrombi}

Table 5 shows the weights of these thrombi, suggesting that the water soaking process would cause larger errors if the thrombus is too small, and smaller errors if the thrombus has a certain weight. The results indicate that weighing the thrombus can be used to evaluate the effect of Coll.-BSA-McAb on thrombolysis in vitro. Heavy thrombi should be chosen in order to minimize the error.

\section{Thrombolysis assay in vitro}

Figure 1 shows the thrombolytic experiment in vitro as described above. Table 6 shows that the thrombus would dissolve by itself in PBS. Figure 6 shows the collagen embolus thrombolysis rate at different time points after the deduction of the blank control.

Table 6 and Figure 6 indicate that Coll.-BSA-McAb immune-conjugate and Coll. could increase the thrombolysis rate in vitro. The thrombolysis effects did not differ significantly between the experimental group (Coll.-BSA-McAb) and the control group (Coll.) $(P>0.05)$, indicating that the process of crosslinking McAb did not affect collagenase activity.

\section{The effect of Coll.-BSA-McAb immune- conjugate on thrombolysis in vivo Establishment of a pulmonary embolism model in rabbits}

We did not find emboli in cardiac artery, while the emboli were partially dissolved in the small pulmonary artery branches. This observation confirmed that the emboli injected reached the pulmonary arterial vasculature and the pulmonary embolism model was successfully established (Figure 7).

\section{Thrombolysis assay in vivo}

Table 7 shows that Coll.-BSA-McAb immune-conjugate and Coll. could both increase the thrombolysis rate in vivo. There was a significant difference $(P<0.05)$ between Coll.-BSA-McAb immune-conjugate and Coll., suggesting that Coll.-BSA-McAb immune-conjugate has a better thrombolysis effect than Coll.

\section{The targeting effect of Coll.-BSA- McAb immune-conjugate Establishment of an ear vein embolism model in rabbits}

Figure 8 shows that that a thrombus was formed, and thus establishing the ear vein embolism model.

\section{FITC-Coll.-BSA-McAb}

We observed the immune-conjugate labeled with a fluorescence microscope after purification. The bright green dot is the collagenase immunizing conjugation labeled by FITC (Figure 9).

\section{Targeting effect}

The thrombus was covered with fluorescence in the image of the experimental group (Figure 11), indicating that collagenase immunizing conjugation labeled by FITC aggregated at the thrombus site. In contrast, there was no fluorescence in the image of the control group (Figure 10). These results indicate that collagenase immunizing conjugation has active targeting effects in vivo.

Table 3 Influence of different cross-linking agents on collagenase activity $(n=3)$

\begin{tabular}{llllll}
\hline Agent & $\mathbf{H}_{2} \mathbf{O}$ & Glutaraldehyde & Succinimide & Acetone & EDCl \\
\hline Concentration & $0.5 \mathrm{~mL}$ & $1.25 \%$ & $1.25 \%$ & $0.5 \mathrm{~mL}$ & $1.25 \%$ \\
$\mathrm{~A}_{566}$ & $0.731 \pm 0.018$ & $0.098 \pm 0.003$ & $0.143 \pm 0.006$ & $0.197 \pm 0.010$ & $0.291 \pm 0.016$ \\
\hline
\end{tabular}


Table 4 Activities of Coll. and McAb in Coll.-McAb and Coll.BSA-McAb $(n=3$, mean \pm SD)

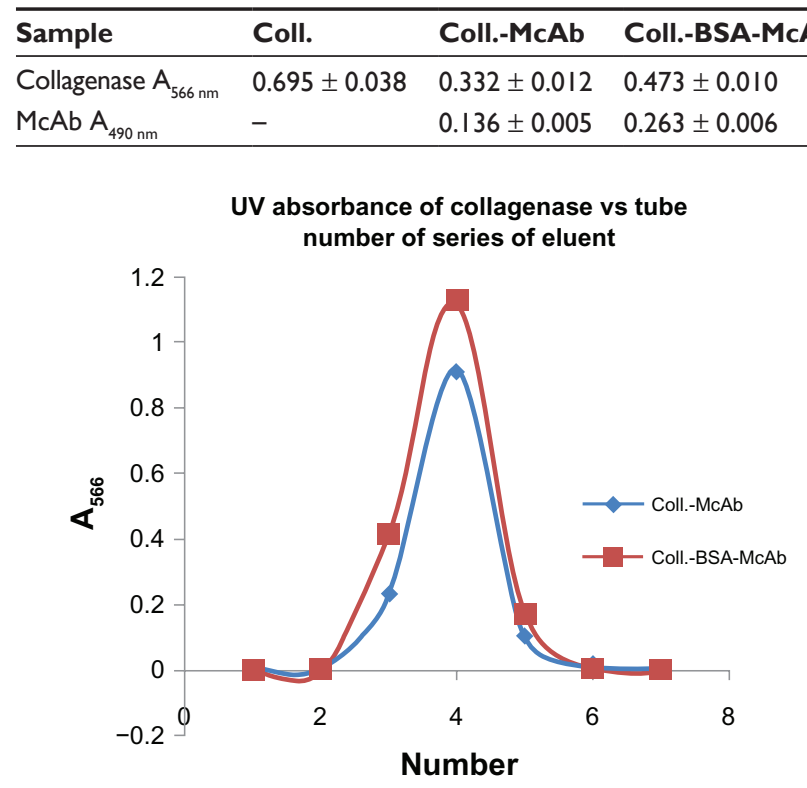

Figure $\mathbf{2}$ The activity of collagenase in an eluent series.

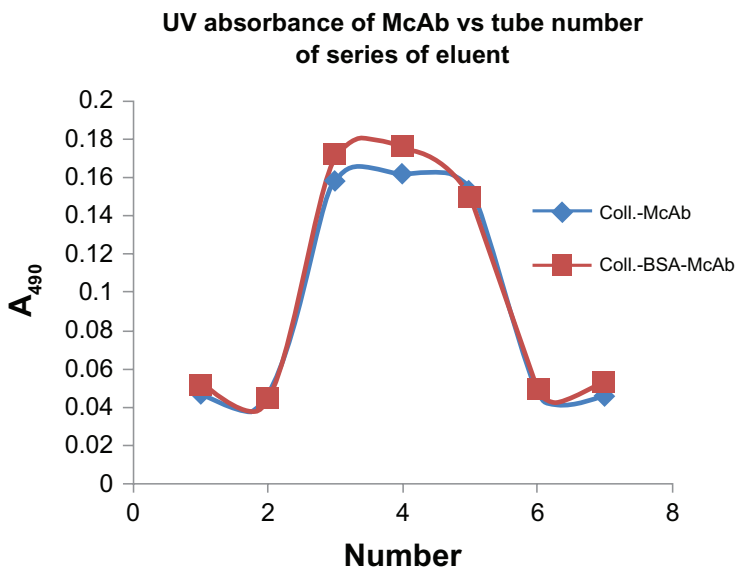

Figure 3 The activity of collagenase in an eluent series.

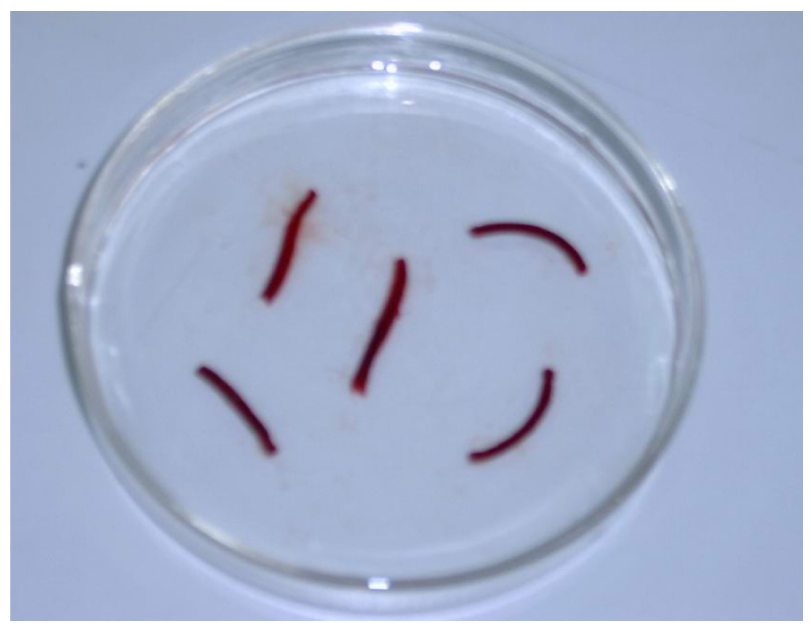

Figure 4 Collagen embolus.

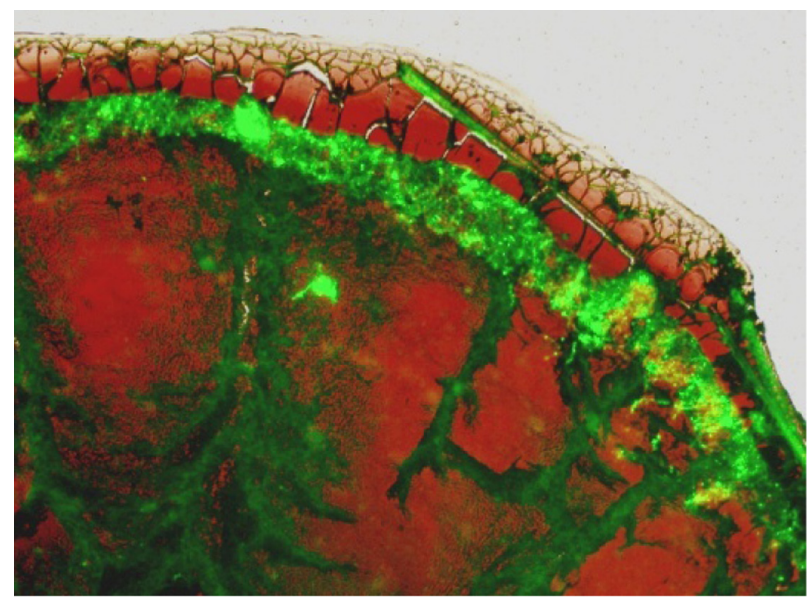

Figure 5 Collagen embolus labeled by FITC.

\section{Discussion}

The EDCI method is a generally mild reaction at $\mathrm{pH} 5.0-9.0$ and at $4{ }^{\circ} \mathrm{C}$ or room temperature. ${ }^{22}$ The reaction mechanism is as follows: an intermediate is produced by the reaction of the protein carboxyl (-COOH) with EDCI, and then the intermediate reacts with the primary amino acid to form a coupled product. ${ }^{22}$ EDCI would not be retained in the conjugate, but transformed into a water-soluble urea derivative with low cytotoxicity. So this method avoids depolymerization and release of the residual toxic substance. Several common crosslinkers, such as glutaralaldehyde, succinimide, acetone and EDCI, have been investigated in our previous studies. Among these, EDCI has the least effect on the activity of collagenase.

Currently, drug-McAb is in short supply ${ }^{23}$ for several reasons. 1) Drug-McAb conjugate can be associated with any other antigen in circulation before it reaches the target site; 2) the chemical bond between drug and monoclonal antibody is destroyed by oxidoreductase and protease in circulation before it reaches the target site; 3) the quantity of drug crosslinking with monoclonal antibody is limited. When the ratio of drug molecules and monoclonal antibody molecules reaches 10:1, it would result in inactivation of monoclonal antibody. If a carrier with many drug and monoclonal antibody binding sites was a linker to conjugate drug and antibody to form drug-linker-McAb conjugation, it might carry more drug molecules and remain active at antigen-binding sites. In this study, our results showed that the activities of collagenase and $\mathrm{McAb}$ were higher in immune-conjugate with BSA as linker than those in Coll.-McAb. This result suggests that BSA as linker to prepare Coll.-BSA-McAb immune-conjugate enables the conjugation to carry more collagenase molecules. 
Table 5 Variance in weight of collagen embolus $(n=3$, mean \pm SD)

\begin{tabular}{lllllll}
\hline No. & Weight $(\mathbf{m g})$ & & & & \\
\cline { 2 - 7 } & $\mathbf{I}$ & $\mathbf{2}$ & $\mathbf{3}$ & 49.6 & $\mathbf{4}$ & $\mathbf{5}$ \\
\hline $\mathrm{I}$ & 64.7 & 52.1 & 46.1 & 2.0 & 13.3 & $\mathbf{6}$ \\
2 & 59.8 & 50.8 & 42.7 & 26.2 & 10.2 & 5.4 \\
3 & 57.2 & 47.2 & $46.1 \pm 3.45$ & $27.7 \pm 3.78$ & $10.8 \pm 2.26$ & 3.9 \\
Average & $60.6 \pm 3.81$ & $50.0 \pm 2.54$ & & & & $5.3 \pm 1.29$ \\
\hline
\end{tabular}

The volume of reaction solution generally increases about 10-fold after passing a GEC column. So the effluent liquid should be enriched to guarantee enough concentration of antibody during the crosslinking. Many methods for enriching protein solution are available, ${ }^{24-32}$ such as lyophilization, vacuum drying, using glucosan to absorb water, the PEG concentration method, ultra-filtration member separation technology, foam fractionation and so on. Here we chose the PEG concentration method to enrich the effluent liquid, since the rate of water absorption was very fast. During the concentration procedure, the solution volume in the dialysis bag should be carefully monitored to avoid overdehydration because the hydrated PEG also has a strong water absorption function.

In our study, a series of thrombi coating collagens were prepared by soaking, blotting dry on filter papers and weighing 3 times. Our results showed that there would be larger errors if the thrombus is too small; and smaller errors would be obtained if the thrombus has a certain weight. Therefore, larger thrombi should be used.

Several thrombus models have been reported, ${ }^{33-36}$ such as rabbit ear vein embolism model, jugular artery/vein thrombosis model, femoral artery/vein thrombosis model, pulmonary embolism model and so on. In our study, we chose the rabbit pulmonary embolism model and the rabbit ear vein embolism model. In the first model, the partially dissolved emboli were found in the small pulmonary artery branches but not in cardiac. We inferred the route of emboli in blood vessels from the investigation as: external jugular vein-jugular vein-superior vena cava-right atrium-right ventricle-pulmonary artery-pulmonary artery branch. The thrombolysis assay in vivo showed that the thrombolysis rate of the Coll.-BSA-McAb/Coll. group was significantly higher than that of the PBS group, and the thrombolysis rate of Coll.-BSA-McAb group was significantly higher than that of Coll. group, which might be due to a sterically hindered protective effect and targeting effect. Besides carrying more collagenase molecules, BSA with a larger volume could protect collagenase from degradation by enzyme in vivo for steric hindrance of group in BSA. In addition, the Coll.-BSA-McAb could aggregate around a thrombus with the help of a monoclonal antibody, which could increase the thrombolysis rate. In contrast, some collagenase molecules without sterically hindered protective activities from vehicle may be degraded by enzyme and deactivated before they arrive in targeted thrombi. Compared with Coll.-BSA-McAb, more free collagenase would be distributed to other tissues for less targeting effect, thereby reducing the effective quantity of collagenase. We speculated on the targeting effect of Coll.BSA-McAb from the statistical difference in thrombolysis rates between Coll.-BSA-McAb and collagenase.

The preparation method of rabbit ear vein embolism model is suitable for studying targeting effect because it is simple and straightforward. Until day 7 after the blood vessel was injured, thrombus organization occurred, indicating that the establishment of the ear vein embolism model was successful and could be used for further experiments. In our study, the injection site was upstream of the embolic site, so the drug solution flowed over the thrombus surface. Then liquor NS solution was slowly injected to remove nonspecific binding. The aggregating of fluorescence at the thrombus site was due to the combination reaction of antigen (collagen) and antibody (anti-collagen monoclonal antibody), which was part of Coll.-BSA-McAb labeled by FITC.

Table 6 Average thrombolysis rate $(\%)$ of collagen embolus $(n=3$, mean \pm SD)

\begin{tabular}{lllllll}
\hline Time (h) & $\mathbf{2}$ & $\mathbf{4}$ & $\mathbf{8}$ & $\mathbf{1 8}$ & $\mathbf{2 0}$ & $\mathbf{2 4}$ \\
\hline Coll.-BSA-McAb & $11.09 \pm 0.49$ & $22.34 \pm 3.09$ & $33.91 \pm 4.16$ & $67.60 \pm 2.10$ & $100.00 \pm 0$ & $100.00 \pm 0$ \\
Coll. & $15.74 \pm 4.39$ & $26.38 \pm 6.73$ & $38.92 \pm 3.36$ & $65.88 \pm 2.39$ & $100.00 \pm 0$ & $100.00 \pm 0$ \\
PBS & $2.41 \pm 1.55$ & $9.28 \pm 0.88$ & $19.63 \pm 6.60$ & $28.70 \pm 8.56$ & $40.00 \pm 8.99$ & $50.93 \pm 6.93$ \\
\hline
\end{tabular}

Notes: Rates of thrombolysis caused by PBS and Coll.-BSA-McAb/Coll. differed signficantly $(P<0.05)$, but rates of thrombolysis caused by Coll.-BSA-McAb and Coll. did $\operatorname{not}(P>0.05)$. 


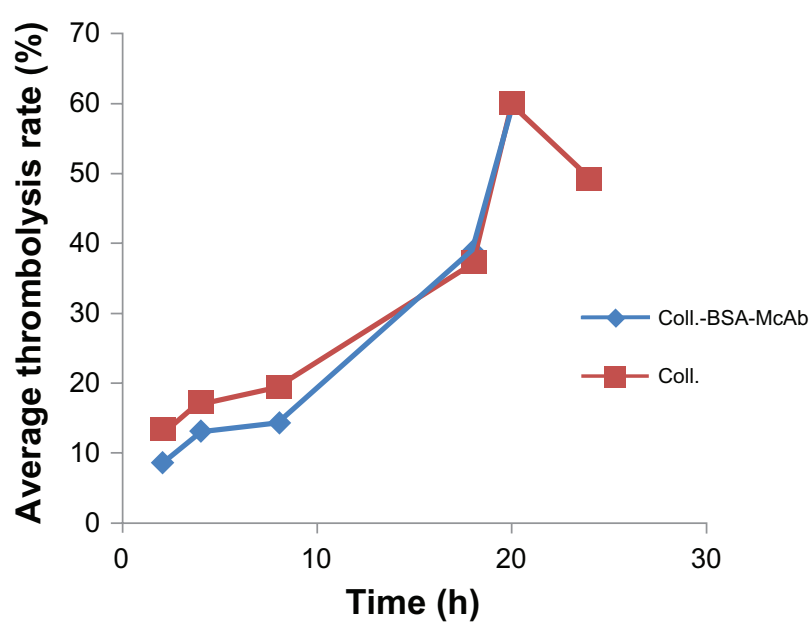

Figure 6 Collagen embolus thrombolysis rate after deduction of the blank control.

\section{Summary}

Coll.-BSA-McAb, an immune-conjugate prepared by the EDCI method, was developed to carry more drug molecules to target thrombi accompanied by a less systematic side effect. In vitro thrombolysis study indicated that collagenase immunizing conjugation can dissolve organized thrombus well, and proved that the process of crosslinking McAb would not influence the activities of collagenase and monoclonal antibody. As a result, Coll.-BSA-McAb was shown to have a better thrombolysis effect than collagenase in vivo. Coll.-BSA-McAb can be oriented specifically to the thrombus via a monoclonal antibody, which was demonstrated by the better thrombolysis effect of Coll.-BSA-McAb than collagenase in vivo and aggregation of fluorescence at the thrombus site. In summary, this study has shown a new approach for developing a monoclonal antibody conjugated collagenase for thrombus targeting.

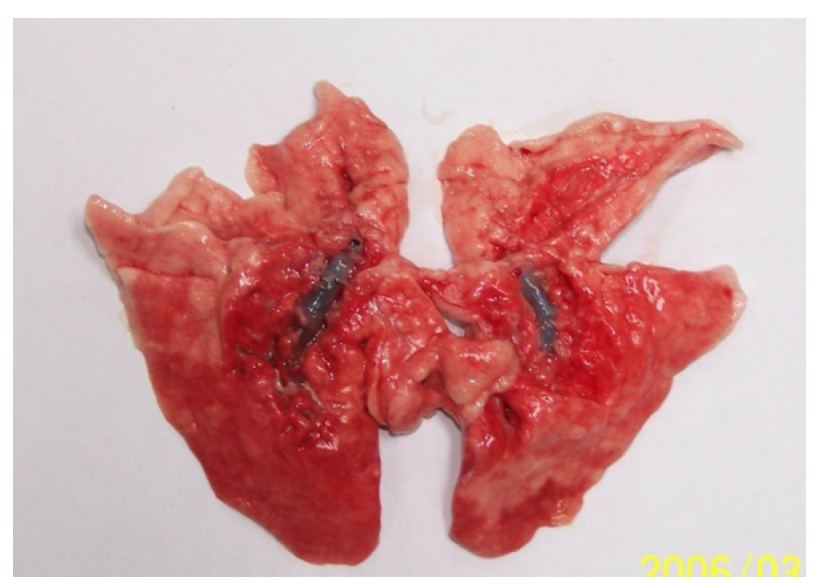

Figure 7 Isolated lung and clots in pulmonary artery.
Table $7 \mathrm{In}$ vivo thrombolysis rates (\%) of rabbit lung thrombosis model $(n=5$, mean $\pm S D)$

\begin{tabular}{llll}
\hline Group & Coll.-BSA-McAb & Coll. & PBS \\
\hline $\begin{array}{l}\text { Average } \\
\text { thrombolysis }\end{array}$ & $78.14 \pm 6.02$ & $65.32 \pm 9.92$ & $49.24 \pm 10.02$ \\
rate (\%) & & & \\
\hline
\end{tabular}

Notes: Rate of thrombolysis caused by PBS and Coll.-BSA-McAb/Coll. differed significantly $(P<0.05)$. Although Coll.-BSA-McAb and Coll. showed similar thrombolytic potencies in rabbit lung thrombosis model, rates of thrombolysis caused by Coll.-BSA-McAb and Coll. differed significantly.

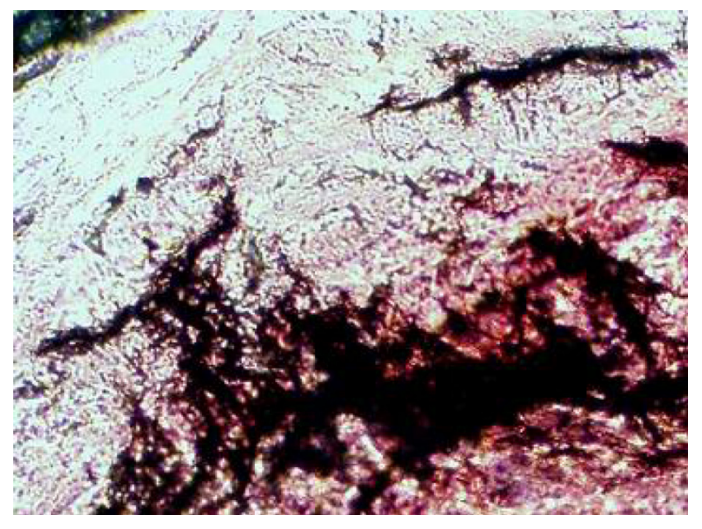

Figure 8 Thrombosis formed in rabbit ear vein.

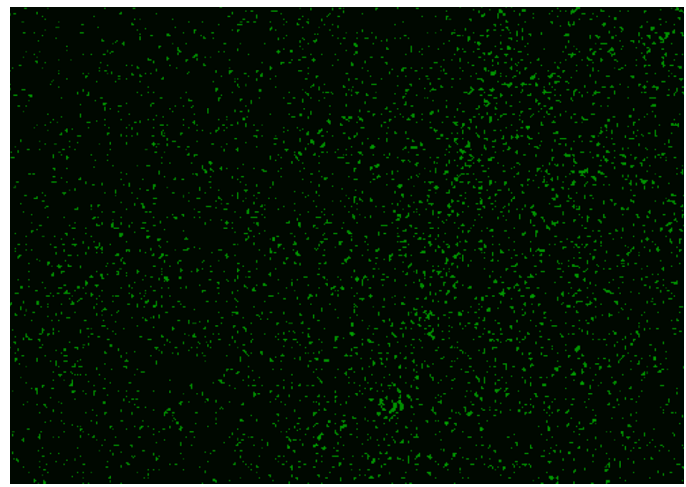

Figure 9 Coll.-BSA-McAb. labeled by FITC.

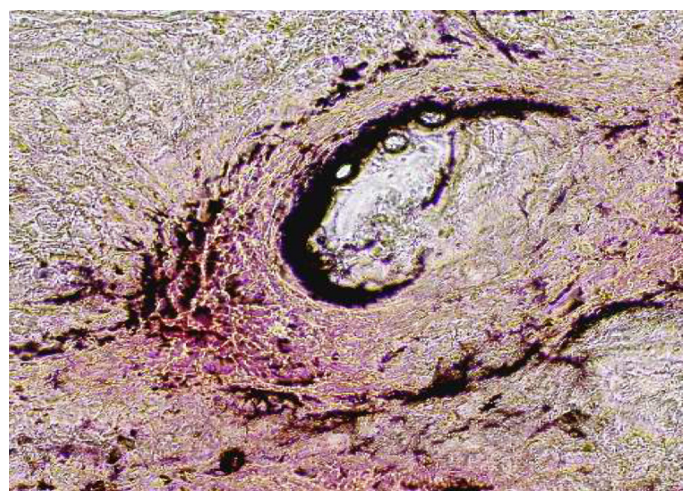

Figure 10 Distribution of collagenase immunizing conjugation labeled by FITC. 


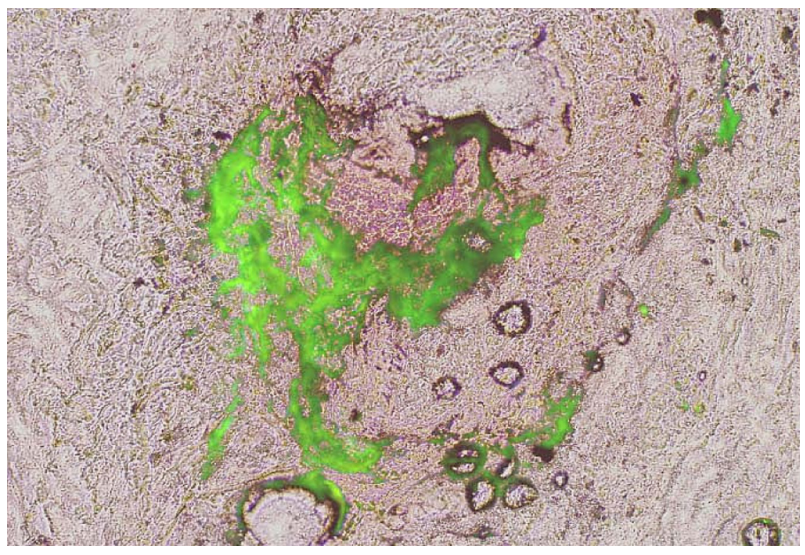

Figure I I Distribution of Coll.-BSA-McAb.

\section{Acknowledgment}

Support for this research was provided by National Nature Science Foundation of China (30371696/H3008).

\section{Disclosure}

The authors disclose no conflicts of interest.

\section{References}

1. Alexander AV, Gregory D, Youri V, Kenneth M, Leonard A, Tiberiu E. Anesthetic implications of the new anticoagulant and antiplatelet drug. J Clin Anesth. 2008;20:228-237.

2. Lange RA, Hillis LD. Antiplatelet therapy for ischemic heart disease. N Engl J Med. 2004;350:277-280.

3. Grines CL. Thrombolytic, antiplatelet, and antithrombotic agents. Am J Cardiol. 1992;70:I18-I26.

4. Verstraete M. Third- generation thrombolytic drug. Am J Med. 2000;109:52-58.

5. Virchow R. Die Cellular-Pathologie. Berlin; 1987.

6. Aschoff L. Das reticulo-endotheliale System. Ergebn Inn Med Kinderheilk. 1924;26:1-118.

7. Feigl W, Susani M, Ulrich W, Matejka M, Losert U, Sinzinger H. Organisation of experimental thrombosis by blood cells. Virchows Arch A Pathol Anat Histopathol. 1985;406:133-148.

8. Schmitt W, Beneke G. Untersuchung zur Lvslickeit von Kollagen durch Plasmin. Wiss Mitt. 336-337.

9. Alberici GF, Marc Pallardy, Luc Mani, Dessaux J-J, Fournier J, Mondesir J-M, et al. Conjugates of elliptinium acetate with mouse monoclonal anti- $\alpha$-fetoprotein antibodies or Fab fragments: in vitro cytotoxic effects upon human hepaoma cells lines. Int J Cancer. 1988;41:309-314.

10. YuiChi Manabe, Teruhiko Tsubota, Yuro Haruta, Morihiro Okazaki, Shigeru Haisa, Kunihiko Nakamura, et al. Production of a monoclonal antibody-blemycin conjugate utilizing dextran T-40 and the antigentargeting cytotoxicity of the conjugate. Biochem Biophys Res Commun. 1983;115:1009-1014.

11. Kulkarni PN, Huntley Blair A, Chose Tarun I. Covalent binding of methotrexate to immunoglobulins and the effects of antibody- linked drug on tumor growth in vivo. Cancer Res. 1981;41: 2700-2706.

12. Hashimoto Y, Endoh H, Sugawara M. Chemical method for the modification of liposomes with proteins or antibodies. In: Gregoriadis G, editor. Liposome Technology. Florida: CRC; 1984:44.
13. Olde Damink LH, Dijkstran PJ, van Luyn MJ, van Wachem PB, Nieuwenhuis P, Feijen. Changes in the mechanical properties of dermal sheep collagen during in vitro degration. $J$ Biomed Mater Res. 1995;29:139-147.

14. Suzuki T, Sato E, Goto K, Katsurada Y, Unno K, Takahashi T. The preparation of mitomycin $\mathrm{C}$, adriamycin and dauromycin covalently bound to antibodies as improved cancer chemotherapeuitic agents. Chem Pharm Bull. 1981;29:844-848.

15. Burstein S, Knapp R. Chemotherpy of murine ovarian carcinoma by methtrexate-antibody conjugates. J Med Chem. 1977;20: 950-952.

16. Jin Y, Luke T, Gary B, Daniel IC. A simple and rapid assay of collagenlike polymer in crude lysate from Escherichia coli.J Microbiol Methods. 2002;49:321-323.

17. Luo ZF, Liu JX, Fan X. Convalent attachment of protein to liposomes by EDCI method. Immunological Journal. 1999;15:125-127.

18. Manuel F, Jose MP, Cesar M, et al. Optimization of the modification of carrier proteins with aminated haptens. J Immunol Methods. 2005;307:144-149.

19. Stephanie G, James AF, Andrew JV. Coupling of diethylenetriamine to carboxyl-terminated magnetic particles. Colloids Surf A Physicochem Eng Asp. 2000;164:257-266.

20. Lip GYH, Chin BSP, Blann AD. Cancer and the prothrombotic state. Lancet Oncol. 2002;3:27-34.

21. Song Ai- li, Dong Xiao- li, Li Liang, Li Rui- fen. Improvement of establishing animal thrombus model method. Journal of Capital University of Medical Sciences. 2002;22:1.

22. Cao Zheng-guo, Li Cheng-zhang. The common protein cross-linking methods and their effects on collagen. Foreign Medical Sciences Biomedical Engineering. 2001;24:187-190.

23. Wu Chuan-bin, Shi Ting-sen. Advances of immune targeted drug delivery system. Progress in Pharmaceutical Sciences. 1993;17: 129-133.

24. Xu Yu-fu, Yao Ri-sheng, Deng Sheng-song. Protein concentration and separation behavior of dextran bulk hydrogels with microstructure. Journal of Chemical Industry and Engineering (China). 2007;58: 3097-3101.

25. He Xi-zhong, Wang Ying, Jiang Feng-ying, Zhou Zong-qing, Zou Yong. Study on concentrating PCV- 2 with PEG- 6000. Acta Agriculturae Shanghai. 2008;24:42-44.

26. Lewis GD, Hough A, Green DH, Hay JE, Ferguson LR. Modification of the polyethylene glycol 6000 precipitation method for recovering human and indicator viruses from oysters and mussels. $N Z J$ Mar Freshwater Res. 1996;30:443-447.

27. Yao Hong-juan, Wang Xiao-lin, Ding Ning. Menbrane sepration technology and its application in purifying and separating the protein. Food Science. 2003;24:167-171.

28. Zhang Yong-feng, Wang Hai, Ma Ning, Cao Jian-Jun, Yu Hai-jiao, Li Qiang. Reclaiming protein in dairy wastewater with ultrafiltration. Chemical Engineering (China). 2009;37:38-41.

29. Hai Jin-ping, Tong Han-jing. Concentration of Chinese Yam protein from the extracted solution by membrane technology. Journal of Anhui Agricultural University. 2000;27:199-201.

30. Liu Zhi-hong, Liu Zheng, Ding Fu-xin, Yuan Nai-ju. Concentration and separation of protein by form fractionation (II). Journal of Tsinghua University. 1998;38:20-22.

31. Rubin E, Garden ELJ. Foam separation. In: Shoen HM, editor. New Chemical Engineering Separation Techniques. New York: John Wiley \& Sons; 1962:320-385.

32. Farooq Uraizee, Ganesan Narsimhan. Foam fractionation of proteins and enzymes: I. Applications. Enzyme Microb Technol. 1990;12: 232-233.

33. Li Shao-ping, Ji Hui, Li Xiao-Xiang. An experimental pulmonary embolus model in rats for evaluation of thrombolytic agents. Journal of China Parmaceutical University. 1996;27:52-54. 
34. Liu Yu, Dong Xiao-Li. Establishment of animal thrombus model. Journal of Capital University of Medical Sciences. 2002;23: 277-280.

35. Chen Tie-Nian, Chen Rui-Fang, Tang Guo-Jie. A simple method of establishing femoral artery thrombosis model in rabbit. 1997;14: $33-34$.
36. Yang Jun, Xi Jiu-Yi. Study on the animal model of deep venous thrombosis at the early stage of thrombus organization. China Journal of Basic Medicine in Traditional Chinese Medicine. 2005;1:199-201.

\section{Publish your work in this journal}

The International Journal of Nanomedicine is an international, peerreviewed journal focusing on the application of nanotechnology in diagnostics, therapeutics, and drug delivery systems throughout the biomedical field. This journal is indexed on PubMed Central, MedLine, CAS, SciSearch ${ }^{\circledR}$, Current Contents ${ }^{\circledR} /$ Clinical Medicine,
Journal Citation Reports/Science Edition, EMBase, Scopus and the Elsevier Bibliographic databases. The manuscript management system is completely online and includes a very quick and fair peer-review system, which is all easy to use. Visit http://www.dovepress.com/ testimonials.php to read real quotes from published authors.

Submit your manuscript here: http://www.dovepress.com/international-journal-of-nanomedicine-journal 